\title{
Solanum viarum Dunal (Solanaceae), Primer Reporte para Honduras
}

\author{
Rodrigo Díaz, Ana C. Samayoa y William A. Overholt ${ }^{1}$
}

\begin{abstract}
Resumen. La maleza invasora Solanum viarum Dunal (Solanaceae) es reportada por primera vez para Honduras. La planta, nativa de Sudamérica, fue localizada en un estacionamiento de la Escuela Agrícola Panamericana, El Zamorano, Honduras, el 26 de noviembre de 2007. Esta maleza es altamente invasora en pasturas debido a que el ganado puede transportar semillas en su tracto digestivo.
\end{abstract}

Palabras clave: Control biológico, maleza invasora, pasturas.

Abstract. The invasive weed Solanum viarum Dunal (Solanaceae) is reported for first time in Honduras. This species, native to South America, was located in a parking lot at the Escuela Agrícola Panamericana, El Zamorano, Honduras, on November $26^{\text {th }}, 2007$. This weed is highly invasive in pastures due to cattle transporting seed in their digestive tract.

Key words: Biological control, invasive weed, rangelands.

\section{Introducción}

Descripción de la planta. Las plantas adultas de Solanum viarum son arbustos de $1-2 \mathrm{~m}$ de alto con espinas de hasta $3 \mathrm{~cm}$ de longitud en las hojas, pecíolos y tallos. Las hojas y tallos son pubescentes y de una contextura pegajosa; las flores son blancas con cinco pétalos recurvados y con estambres color amarillo (Ferrel y Mullahey 2006). Las frutas inmaduras son de color verde pálido a oscuro con un patrón moteado como una sandia. Las frutas maduras son amarillas y de 1 a $3 \mathrm{~cm}$ de diámetro con una cáscara blanda y tienen de 180 y 420 semillas planas de color rojizo-café (Ferrel y Mullahey 2006).

Distribución geográfica. Solanum viarum es considerada nativa de la zonas tropicales y subtropicales de Brasil, Argentina, Paraguay y Uruguay. La planta está presente como especie exótica en África tropical, zonas templadas y tropicales de Asia, Estados Unidos, México (GRIN 2008) y Centro América (Medal 1996)

Problemas reportados en Estados Unidos. Solanum viarum fue descubierta en Florida en 1988 y es considerada una de las malezas más destructivas en zonas ganaderas. La planta se ha esparcido rápidamente debido en gran parte al transporte de ganado desde Florida hacia los estados adyacentes (Ferrel y Mullahey 2006). Otras formas de transporte incluyen grama, heno y estiércol contaminados con semillas. Si esta maleza no es controlada la cantidad de cabezas de ganado por área es reducida, lo que sube los costos de producción. Solanum viarum es hospedero de algunos virus del mosaico que atacan vegetales como el tomate, tabaco y berenjena (McGovern et al. 1996). Adicionalmente, otras plagas insectiles que utilizan $S$. viarum como hospedero incluyen los lepidópteros Manduca sexta, Leptinotarsa decemlineata y Helicoverpa virescens, el áfido Myzus persicae, la mosca blanca Bemisia spp., y la chinche Nezara viridula (Sudbrink et al. 2000).

Nuevo reporte para Honduras. Una planta de 30 $\mathrm{cm}$ de altura y con frutos fue colectada el 26 de noviembre de 2007 en el estacionamiento del edificio de la carrera de Desarrollo Socio Económico y Ambiente ( $\mathrm{N} 14^{\circ} 00^{\prime} 36.5^{\prime \prime}$ O 8700'59.7'), en El Zamorano, Honduras. La identificación es el Dr. Richard Weaver del Department of Plant Industries,

\footnotetext{
${ }^{1}$ Biological Control Research and Containment Laboratory, University of Florida, Fort Pierce, Florida 34945
} 
Florida Department of Agriculture and Consumer Services. El material fue depositado en la colección de plantas del Department of Plant Industries con código Rodrigo Diaz B-2007-782. A pesar de haber sido reportada en Guatemala y Nicaragua (Medal comunicación personal), este reporte es el primer espécimen de centro América archivado en un herbario.

Control biológico de Solanum viarum. Debido al problema creado por esta maleza en el sur de Estados Unidos, un programa de control biológico clásico fue iniciado en 1994 (Medal 1996). Luego de varios años de exploraciones en Paraguay y el norte de Argentina y ensayos de especificidad; el crisomélido Gratiana boliviana Spaeth fue liberado en Florida en mayo de 2003. Resultados iniciales parecen prometedores con defoliaciones del 20-100\% en algunos sitios (Medal et al. 2006). Otros organismos usados como agentes de control biológico de Solanum viarum incluyen los virus del mosaico en forma de bioherbicidas (Ferrel et al. 2008).

Agradecimientos. Expresamos nuestro agradecimiento al Dr. Richard Weaver de DPI, FDACS, Florida por la identificación y catálogo de esta colecta.

\section{Bibliografía}

Ferrel J.A. y Mullahey J.J. 2006. Tropical Soda Apple (Solanum viarum Dunal) in Florida. EDIS publication. University of Florida [Internet: http://edis.ifas.ufl.edu/WG201] (20 de febrero de 2008).

Ferrell J., Charudattan R., Elliott M. y Hiebert E. 2008. Effects of Selected Herbicides on the Efficacy of Tobacco Mild Green Mosaic Virus to Control Tropical Soda Apple (Solanum viarum). Weed Science 56: 128132.
GRIN. 2008. USDA, ARS, National Genetic Resources Program. Germplasm Resources Information Network. National Germplasm Resources Laboratory, Beltsville, Maryland. [Online Database: http://www.arsgrin.gov/cgi-bin/npgs/html/taxon.pl?317433] (20 de febrero de 2008).

McGovern R.J., Polston J.E. y Mullahey J.J. 1996. Tropical soda apple (Solanum viarum Dunal): Host of tomato, pepper, and tobacco viruses in Florida. In: Mullahey JJ, editor. Proceedings of the Tropical Soda Apple Symposium, 9-10 January. Bartow, Florida. University of Florida-IFAS. Gainesville, FL. p. 31-34.

Medal J.C., Charudatan R., Mullahey J.J., Pitelli R.A. 1996. An exploratory insect survey of tropical soda apple in Brazil and Paraguay. Florida Entomologist 79: 70-73

Medal, J.C., Pitelli, R.A., Santana, A., Gandolfo, D., Gravena, R. y Habeck D.H.. 1999. Host specificity of Metriona eliator, a potential biological control agent of tropical soda apple, Solanum viarum, in the USA. BioControl. 33:421-436.

Medal J., Overholt W., Stansly P., Osborne L., Roda A., Chong J., Gaskalla R., Burns E., Hibbard K., Sellers B., Gioeli K., Munyan S., Gandolfo D., Hight S. y Cuda J. 2006. Classical Biological Control of Tropical Soda Apple in the USA. Entomology and Nematology Department, Florida Cooperative Extension Service, Institute of Food and Agricultural Sciences, University of Florida. [Internet: http://edis.ifas.ufl.edu/IN457] (20 de febrero de 2008).

Sudbrink, Jr., D.L., Snodgrass G.L., Bryson C.T. Medal J.C., Cuda J.P. y Gandolfo D. 2000. Arthropods associated with tropical soda apple, Solanum viarum in the Southeastern USA, p. 247- 248. In Spencer, N.R. (ed.). Proceedings of the $\mathrm{X}$ International Symposium on Biological Control of Weeds, July 4-14, 1999, Bozeman, Montana. Montana State University, Bozeman, Montana, United States.

Recibido para publicación el 26 de febrero de 2008 